\title{
The Role of School Management Teams in Underperforming Schools: A Matter of Values
}

\author{
Setlhodi-Mohapi Itumeleng I \\ Lebeloane Ldm "Oupa" \\ College of Education, University of South Africa, South Africa
}

\author{
Doi:10.5901/mjss.2014.v5n3p475
}

\begin{abstract}
There is a strong link between a value laden school, a School Management Team (SMT) and school performance. Schools require a management team that is able to steer agreed upon values that can underlie performance in order that teachers teach, learners learn and stakeholders provide requisite support. The intention is to get an underperforming school to progress from poor to fair, to good and ultimately to excellence. This study sought to highlight the extent to which desired performance and shared values are mutually connected in eradicating underperformance. This article synthesises on the study and provides a perspective on the SMTs role in driving the establishment of agreeable values and ethos that are consistently reflected in all its operations and activities in order to maintain an upward performance.
\end{abstract}

Keywords: Underperforming schools; Role of school management teams (smts); Values; African perspective; Leadership, administration and management of schools; Academic performance improvement; Capacity building; Attitude; Monitoring and support

\section{Introduction}

South Africa continues to battle the challenge of underperformance in schools that are predominantly situated in socioeconomically unfavourable settings. Performance improvement remains high on the agenda particularly at grade 12 senior certificate level. Underperformance is mainly a thorny issue in previously disadvantaged schools that serve learners from predominantly poor communities. It is widely recognised that good performance draws more learners to the school and guarantees them an opportunity to turn around their socio-economic status, particularly those from impoverished backgrounds. This implies that education, which is itself a value, can be leverage for social redress.

This study sought to uncover mechanisms that would enable SMTs of underperforming secondary schools in Gauteng West District to brand distinctive values (agreeable to all stakeholders) that would enable them to serve as vanguards of strategies (presented as guidelines) meant to exterminate underperformance. The study further (attempted) exposed the interconnectedness between desired performance and the importance of shared values in eradicating the problem of underperformance.

The approach was to unearth the interconnected nature of excellent performance with values as the codes that hold all the stakeholders on the cause of quality performance with the sole purpose of ensuring that learners learn, teachers teach, managers manage and the stakeholders provide required support. The researcher drew from the African perspective in uncovering the essence of role-modelling essential values, with an intention to raise the will by all stakeholders to improve performance, particularly in an underperforming school. Values among Africans reinforce conduct and are therefore integral for organisations to prescribing what is important, desirable and worthy and as a result, surpass conditions or relations. Schuitema (2004b: 5) declares that they regulate peoples' actions at any given time. This implies values or the lack thereof, account for prevailing situations in any setting and for that reason should be considered when seeking to address a particular purpose in this instance, attempting to improve performance.

The purpose of this article is to outline the significant characteristics of values and the role the School Management Team (SMT) in an underperforming school can play by branding agreeable values and incorporating them in all operations and activities. The worth of theorising the findings in this instance is that it will enable learning in other underperforming schools locally, nationally and internationally. The findings are not setting bound, to that end they have international significance and relevance particularly in relation the code of relations and influence as outlined in this paper.

The paper describes the background and context of the study, review the relevant literature, explain the research 
methodology and summarise and interpret the main findings.

\section{Background and Context}

Underperforming schools are presently faced with a challenge of producing and maintaining quality performance internationally and particularly in South Africa (Phorabatho, 2010: 20-21; Mckancy Report, 2010). Most of these schools serve learners from impoverished communities requiring education to set up opportunities that would give them breakthroughs to a better life. There exist a strong connection between mediocre academic performance and injurious livelihoods (James, Cannolly, Dunning \& Elliot, 2008: 66; Ramphele, 2012: 34 - 3). The National Planning Commission (NPC) has exposed the fact that education is below par for learners coming from poorer communities compared to their counterparts from affluent areas in South Africa and that efforts to improve the standard of performance in disadvantaged schools has failed (NPC plan, 2011). This is also the case in the USA as well as in England (MGSLG, 2011: 36; http://www.bbc.co.uk/news/education-11331574-accessed-18 September 2010 respectively). The challenge could (particularly in South Africa) be attributed to unproductive leadership corps that is unable to overcome challenges impeding performance. Those in leadership in underperforming schools operate within a context that is complex and may to some extent be turbulent as well. Underperforming schools according to Quality Assurance Directorate Report (QADR) (2010: 19 - 21) endure the following features:

a. They are located in historically disadvantaged areas (township) and / or predominantly serve learners from these areas / background.

b. Internal conflicts amongst the School Management Teams (SMTs) reflect: lack of team work, sow divisions amongst staff members and other stakeholders. This impacts on the school progress;

c. No effective development, monitoring and support by the SMTs;

d. Systems of control (for both learners and teachers) have either not been established or are ineffective and there are no agreed upon guiding principles; and

e. Poor leadership and management, which was said to be the "direct root cause for underperformance" Quality Assurance Directorate Report.

These reasons denote a troubled leadership that lacks normative, proficient and values based practices resulting into unwarranted performance. Despite all these causes, they (the leadership) are increasingly pressured to improve and rise above them. How can they do it?

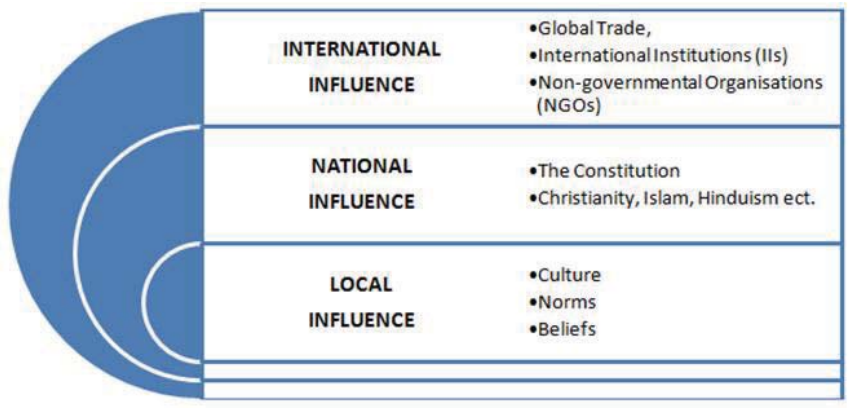

Figure 1. The code of Relations and Influence

The school setting is a microcosm of beliefs, norms and values comprising of people across the length and breadth of South Africa and beyond. This is where the local, national and international codes of influence originate. Gauteng West District in this context is an area where predominantly Batswana tribe reside, having their own beliefs and value system. There are also people from other parts of the country and including other countries who also have their own values, cultures and beliefs. This fusion causes a unique set of existing culture, norms, values and beliefs exclusive to this area. The latter form the source of the school culture in this locality. The second ring of influence stems from cultures such as: the Afrikaaner, English and other foreign cultures; norms which may come from the media and other networks; beliefs that are faith / religion based; and the South African legal system which has an influence of the Roman Dutch law. The last code of influence comprises the South African government statutes which are influenced by international demands, 
business both at local and international level as well as non-governmental organisations. These three rings of influence together with trade (import and export) principles have a bearing on the Gauteng West locality which in turn affects the school context. In turn, the proceeding influences the school populace and including performance. There is a need on this ground for South Africa generally and Gauteng West in particular to wrestle the trials and tribulations brought about by these influences. Lessons could be drawn from countries such as Brazil (which is part of BRICS of which South Africa is part of), which managed to set a momentum to accelerate performance improvement initiative through periodic performance assessment drive (Grobbelaar, 2011: 9).

In South Africa, principals are required to provide a report on their school's academic performance according to the South African Schools Act 84 (SASA) (1996; 16A (1) b). This will then, depending on the performance of the school, warrant the Head of Department $(\mathrm{HoD})$ to determine the performance of the school and in writing notify the school whose learner performance is below requirements in line with section 58B (1\&2) SASA. The SMT, led by the principal, should as a result develop an Academic Performance Improvement Plan APIP (APIP) (circular 25: 2008) that will guide activities meant to improve performance in underperforming schools (circular 15: 2009). The responsibilities of the SMT in this regard are stated in circular 38/ 2007 regarding measures to be taken (by the SMT) to improve performance. Additional to the APIP, the SMT is required to develop a School Improvement Plan (SIP) in line with Resolution 8: 2003 in relation to Integrated Quality Management System (IQMS) which focuses on the development of teachers including the SMT (teachers with managerial responsibilities). Again, the School Governing Body (SGB) should ensure that a School Development Plan (SDP), which gives direction to whole school development initiatives, is generated from the school objectives stemming from the vision and mission statements.

In light of the above, the SMT is required to provide leadership that will bring about desired performance. This makes them (SMT) directly liable to add value and raise the performance bar. Various authors (Leithwood, Day, Sammons, Harris and Hopkins, 2006: 14; Bush, Kiggundu and Moorosi, 2011: 31; Mckinsey \& compony, 2010 \& Morris 2010) contend that performance improvement remains the responsibility of the leadership within a school. This implies that the SMTs of underperforming schools are predisposed to provide visionary leadership in their quest to bring performance at the cutting - edge. The basis of solid collective drive to any initiative in the African context depends on the agreeable culture, norms, beliefs and values espoused. Values according to Singo (2003: 23) are affirmations specifying measures to be undertaken towards accomplishing a particular cause, in this instance tackling underperformance. Ramphele (2012: 61) concedes by stating that values distinguish Africans from other populations and further elaborates that they (values) determine suitable parameters for conduct, practices and attitude.

The fact that underperforming schools are mainly serving clients from previously disadvantaged backgrounds, which in the main comprise of Africans, implies that the SMT of an underperforming school should consider branding agreeable values for their institution and punt them through the operations and activities of the school in order to move their school from poor to fair, to good and to excellent. This should be through plans (APIP, SIP and SDP) seeking to address conduct, practices as well as attitudes to ensure that learners learn, teachers teach, managers manage and stakeholders provide the necessary support for performance to improve. Meaning, attitudes that are characterised by resolute improvement drives and the attainment of quality performance will translate into a teaching and learning environment characterised by a collegial conviction of set conventions permeating in underperforming schools.

The conventions mooted relate to the agreeable principles embraced by all parties in the underperforming school. There is a need by the SMT in this instance to push for means that will form a base for their improvement initiative. According to Bush (2007: 400) values establish a practice or moral consignment which is a rule of conduct or behaviour that bestows principles within a setting. For that reason, an agreeable practice is honed on shared values that are a code of performance improvement. As a result, values will arguably commit those agreeable to them to a continued forward momentum of growth and advancement. This will lead to qualitative improved performance.

\section{The Need to Tackle Underperformance}

The growing insistence on attaining high performance regardless of the context of the school implies that the stakes of advancement are placed on investing in the education of children to take forward the course of developing humanity. A theoretical framework based on reconstructionism by philosophers such as Dewey (1916) and Frere (1973) points to the fact that schools at large and education in particular make it possible for people to interact with their actual state of being and subsequently provide them with skills that would capacitate them to deal with life challenges. Karl Marx (1847) offers that the dynamics and relational characteristics distinctly distinguish value phenomena. The effort or lack of it accounts to the nature of performance that is either susceptible or incomprehensive. Inability to deal with underperformance suggests 
that the anticipated improvement coming with being skilled and knowledgeable remains a pipe dream. The leadership role within a setting where there is a performance dip is obligated to reflect on the existing culture that has caused underperformance and should be courageous enough to strengthen enriched abilities needed to redress performance. Ngami (2011: 58) suggests a leadership behaviour that positively influences conduct. The leadership (SMT) has to be authentic and sentient the values of their institution (Schuitema, 2004a: 50).

Values underpin the course a school seeks to undertake in enriching the quality of results (Bell \& Chan, 2005: 10). They (values) induce sufficient ground for the resurgence of courage and resilience intently meant to advance the will for growth and coining of a success formula. The values held by individuals' impact measurably large on activities within a setting. On that basis, a framework that places institutional agreeable values outlook should be developed. Institutionalising values has become a compelling reason to bring success (Values Mate poster, 2010). Shared values enjoin a management philosophy that sets to cultivate an on-going review of deliverables as well as a strong conviction to do things right rather than doing the right thing (Schuitema, 2004a: 51 - 53). The leadership can use them (shared values) to counter debilitating performance turmoil by mobilising the capabilities of the staff through plans that will give effect to competitiveness. Through values, performance can be boosted by way of key considerations to results - yield. Considering factors such as; empowerment through values, courage and resilience, expressing care and compassion and operate in meaning and purpose (Moloi, 2005: 60). These have to resemble a strong cooperate ideology exemplifying a set of fundamental beliefs held by all stakeholders (Begley \& Leonard, 1999: 181; Beare, 2001: 19-20; Schreuder \& Landey, 2001: 31; Brooderyk, 2006: 26; Maxwell, 2010: 209). Such beliefs shape decisions and direct conduct and are informed by the indigenous knowledge system innate within the school context. They form a founding base of values that necessitate a change in the manner in which the underperforming school should operate. Vision setting, that in - cooperate values shared by all stakeholders has to be an all-encompassing factor to wade off underperformance.

The vision of a school is a driving statement of intent, developed with the sole purpose of pronouncing the direction the school is headed. The vision has to make it possible for the SMT of underperforming schools in Gauteng West District to fathom where trends are headed in education and for that reason think globally whilst acting locally. It (vision) hinges on values. The role of the SMT in this instance is to brand agreed upon values to counter underperformance.

\section{The SMT Role in Creating Counter-Trend of Underperformance}

The function of the management team fraught with underperformance is to rid their institution off the unsighted paradigms that taint performance. This suggests that they need to zoom in the sort of attitudes, beliefs and/ or practices that keep entrenching underperformance tendencies. Upon that basis, they have to come up with indigenous knowledge systems, based on envisaged ethos. Rintoul and Goulais (2010) argue that there is a need for the development of administrative moral compass to perfect ethical principles that will enable desire to perform. As soon as the ethics warranted are established, the SMT should brand and spearhead co-ordination of moral values until they become recognised codes. These codes should symbolise the collaboration marked by the interdependent-ness of all stakeholders. A relationship derived from all parties within the school can be associated to a three legged African pot whose legs each represent learners, teachers and parents respectively. Each leg supports the pot cooking (teaching and learning) in a ground fire (ethos) until it is cooked. The pot is termed "pitsa" in Setswana (indigenous language in South Africa). According to Brooderyk (2006:117) the "pitseng" (African pot) analogy, is about everyone doing their work and adhering to their responsibilities. Accountability and responding to responsibilities form the basis of what is termed the African culture. By dispensing off with their responsibilities (punting values), the SMT will be able to harness attributes individuals bring along to build human relations, conveying Ubuntu to a sharp focus.

\subsection{Ubuntu}

Ubuntu is an African philosophy that offers the coming to grips with Africans' world view (Panse, accessed - 04/05/2011). Being humane is central to Ubuntu philosophy. Its origin can be traced from the word muntu (in Isizulu - one of the indigenous languages in South Africa, meaning a human being). Mbiti (1990: 11) surmises Jahn's work (1958 in Mbiti) regarding African philosophy - which he bases on Kagame's work referring to Muntu: includes God, spirits, the diseased and human beings; kintu: forces commanded by Muntu; Hantu: depicting time and space; and Kuntu : focusing on the aesthetic. The ntu resembles extra-terrestrial vastness (metaphisics - relating to the cosmos), where the being and 
beings fuse. The conception of Ubuntu, it can be argued, has its depth stemming from the conception of where the being and beings coalesce. Ubuntu is arguably the essence of a life marked by consideration for fellow humans and other beings. The question is: How can Ubuntu become a sublime brand of shared values?

Humanness is at the core of Ubuntu philosophy. Its origin is characterised by humanistic culture. It is being. Existence among Africans is premised upon a religious phenomenon. This religion is ascribed to African ontology for which Mbiti (1990: 15-16) categorised into five and of which man is at the centre. They are: God; spirits; man; animals and plants; as well as phenomena and objects Ibid. The Humanistic culture is centred on values. Brooderyk (2006: 31) postulates that humanness marks the practice of sincerity from which humanity prevail as an act of goodwill, which in turn is a wilful effort of benevolence. It is a disposition to embrace human dignity. Human dignity is a right enshrined in the Constitution of South Africa (1996, section 10) beholding the protection of respect. According to Wessels (2007: 28), there is a divergent view of what is the fundamental value between human dignity and equality, therefore upon that base; people have a prospect of their state of being using values as their lens. Both these values (human dignity and equality) are South African Constitutional values. They offer understanding of connectedness and affirmation of the need for humanness which is symbolic of Ubuntu. Ramphele (2012: 61) contends that Ubuntu is an assertion of humans being interconnected and for that reason, validates human dignity. The connection contended marks the base for designating shared values as a symbol for operational intent when managing performance, whereby Ubuntu is set at the core of operations.

Once the shared values are internalised, there has to be a calibration of measures that will support appropriate attitude based on humane performance improvement drive. The SMT has to exert a coercive pressure incisively with an intention to cause a rapid upsurge of warranted performance. Such persistent act can be amassed through branding agreed upon values distinctive to their setting. There should be an understanding of the manner in which operations will unfold by all stakeholders. The SMT should strike a balance between purposive transfer of skills as well as exposing staff to a high level skilling endeavour informed by in-depth competence review of their (staff) abilities. In the interest of achieving this, they should coin suitable values, managers should probe whether individual and educators values demonstrate the importance of caring that permeate the will to embrace Constitutional values MGSLG (2011: 14). A school that seeks to excel should be underpinned by amongst others, these values. They (Constitutional values) need to underlie firstly the culture within a school and secondly social constructs for efficacious performance to be realised.

The above postulate relooking requisite features of performance outlined for Gauteng West underperforming schools through the Whole School Evaluation (WSE) policy (2001) as well as the Integrated Quality Management System (IQMS) Resolution 8 (2003) which form the legislative framework for continued requisite performance and development. The performance backdrop in this instance encompasses organisational behaviour, quality management as well as performance management as the stamp hallmark covering performance ground, informing school improvement and steering learning.

\section{Prominent Features Affecting Performance}

The state of education in South Africa as stated in the National Planning Commission (NPC) is amongst the top challenges raised requiring strategic objectives for improvement. According to the NPC, education for poor, black South Africans is substandard, "only $1 \%$ of African schools score top performing high school result, while $31 \%$ of other schools are top performers" (Sunday Times, 2011: 8). The NPC has uncovered that the efforts lined up to improve the quality of education for previously disadvantaged schools have to a large extent failed. The quality of school leadership as well as teacher performance are said to be key factors that have resulted into education outcomes being poor yet no one is directly answerable Ibis. Winter (2011: 19) contends it is inopportune truth that different studies have concluded - in South African schools - that underperformance is as a result of failure to hold teaching professionals accountable.

Given the above, the school management of underperforming schools are confronted with dilemmas that continue to arrogate efforts that are geared at achieving their purpose (good performance). Their composition is honed with the legacy of the previous dispensation lingering on and continuing to haunt them. Their structures limit them in terms of having essential specialist classrooms / centres such as laboratories and libraries amongst others (Vally, Chisholm \& Motala, 1999: 8; Bloch, 2011: 5). Those that have these utilities are used for purposes contrary to what they are meant for because they are either under or not resourced. Underutilising or poor utilisation of facilities as a result of lack of resources or failure to account contribute to a large extent to poor performance. It is so because these schools are unable to innovate and look for alternative means in trying to complement and / or make up for what they don't have. This is what sets them (these schools) apart from their counterparts who innovate and use whatever they have optimally. 
Despite the above challenges, the bulk of the budget from National Treasury goes to salaries and only $20 \%$ is allocated for important educational resources such as textbooks and other amenities (Winter, 2011: 19).

Poor performance could also be as a result of inferior policy implementation support from the district as well as provincial offices. Phorabatho (2010:60) corroborates by pointing at disconnect between policy and implementation. The contrast is brought about by the fact that those who are meant to support schools are themselves unconfident (because they lack the skills) to interpret (policy) and to that end provide the necessary support to underperforming schools. The Education Handbook (2011: 88) presents that challenges of school leaders are compounded by the expectation to implement complex policy prescripts and every so often with little support and/ or training. This problem was raised by the unions during Soweto summit as a factor that needed urgent attention (Summit Document, 2011) by the Department of Basic Education. Failure to heed this challenge may lead to lack of effectiveness and on point support being provided to underperforming schools in particular. The results may lead to lack of confidence in officials who are meant to support schools, further leading to unproductive tendencies (Phorabatho, 2010: 61).

Changing the habit of poor performance with an intention of ensuring the initiation of appropriate performance standards remains a challenge (Fidler \& Atton, 1999:m36). Schools that continue to perform poorly, fail in an array of situations they should be competent in. It is against this background arguably, that there is a compelling need for focused support that will enable such schools to work themselves out of their underperformance plight. The school's state may be due to poor results which are because of the poor decision/s taken years prior to the actual results; subject choice of learners as a result of poor advise or lack thereof; factors such as social, economic, political and technological challenges on both learners and teachers; as well as unwarranted conduct as a result of the foregoing factors. The leadership of such schools may themselves be unable to bounce back. This is why they (SMTs) need professional support from the DBE Provincial and District offices.

The above situation is indicative of a need for incremental improvement in the manner which the SMT leads and manages their schools. However, the fact that they may be contaminated (by underperformance) themselves means that they require assistance to win themselves out of underperformance. This calls for the SMT to seek support in order for them to be enabled to reboot performance. This means they have to be intensely tenacious in eradicating underperformance by mapping a sustainable improvement course that will take them from poor to fair, then to good and ultimately to excellent performance (McKenzie Report, 2010: 8). To pull off this kind of performance means that the SMT of underperforming secondary school should sequentially pile up daily doses of value added activities that will rise over a period of time into gainful accomplishments (Sharma, 2010: 36).

\section{Design and Methodology for Branding Values to Combat Underperformance}

A qualitative research methodology was used to elicit the views of SMT members, teachers and School Governing Bodies (SGB's) regarding the role of SMT's in branding shared values with an intention to turn around underperformance in their schools. The probed schools were called cases. Interviews were conducted in three cases with individual principals and focus groups (comprised of SMT members, teachers who were teaching grade 12 in 2011 and SGB members) per case. One case was observed over a period of eight months. Documents such as the SMT minutes (January 2011 to June 2012), Quality Assurance Reports (QAR - January 2012), Academic Performance Improvement Plans (APIP), panellist documentation as well as the West Rand Education Portfolio Committee Report (2011) on underperforming schools were analysed in all three cases. Each case had a panellist, whose responsibility was to document the SMT activities over four weeks (the period was extended to first week of term three). Ethnography was the lens with which this study was conducted. Relevant literature was used as the basis of data collection.

Data collection explored the respondents' views regarding the role of the SMT in an underperforming school when punting agreeable values to redress performance that is below par.

\section{The Findings}

\subsection{Tackling underperformance: the role of the SMT in branding values and values theory}

The main aim of this study was to uncover mechanisms SMTs of underperforming schools in Gauteng West District could apply in branding values (agreeable to all stakeholders) that would enable them to eradicate underperformance. Literature and Theoretical views on underperformance and school improvement point to the fact that the role of the leadership (SMT) within the school is paramount in overseeing performance improvement. The inference is that: 
* A value driven leadership precipitates a connection to clients, conveying the institutional culture regarding envisioned performance. This will influence desired attitude, lending credence to the significance of collective effort as well as relentless continuous performance improvement initiative.

* Values branding will also permeate the increment of performance from poor to fair to good and ultimately to excellence through harnessing relationships and influencing conduct that will be the guiding code improving performance.

* Ubuntu

\subsection{Performance and capacity building agenda: countering causes of underperformance through values branding}

Performance and capacity building agenda focused on the reasons for and measures to counter underperformance. These exposed the need for SMTs of underperforming schools to develop guidelines for improvement of performance. The implication is that the SMT require specific abilities that will enable them to lift the lid on underperformance by: strategising; continuously seeking improvement possibilities; winning stakeholders' support; designing a possible improvement model; learning whilst implementing strategies; and calling for support from the District and Provincial offices when the need arises. The attributes resembling the guidelines required by the SMTs of underperforming schools, in line with the literature reviewed are:

* The principal should provide requisite leadership to the SMT in setting achievable targets.

* The SMT should through authority entrusted in them, give direction in operationalizing activities to achieve set targets.

* The SMT, in providing leadership, should concentrate on the principles (shared values) that seek to support stakeholders in ensuring that teaching and learning take place in a supportive environment.

* The SMT should 'plant seeds' (branding afore mentioned shared values) that will enable their institution to blossom into expected change by maintaining human dignity and affirming the interconnectedness as well as humanness the African culture propagate, symbolising Ubuntu.

* The SMT continuously review and evaluate activities, so that there is accountability.

* The SMT should consider the push and pull factor of the code of relations and influence (stated in figure 1) in branding shared values and harnessing sound relationships.

* High achieving leaders are learners. The SMT should keep their sickles sharp (abreast with developments within their area of specialty) so that they: remain relevant and competent in their work, exude the capacity to develop, coach, mentor and support others. The School Governing Body also requires development in order to provide leadership that will enable the school to raise the performance bar.

* Incorporate shared values (generated during strategy development process) into the systems set. This is because values in Africa serve as assegais to manage and maintain that which seeks to advance a particular course (in this instance improvement of results) as well as defend and influence relations (Brooderyk, 2006: 27).

The above form part of the aims of the study and should resemble the segments (that will be the gestalt in this instance) that will groove improvement pathways, bringing about whole school performance improvement.

\subsection{Design and Qualitative methodology in branding values to combat underperformance}

The design embarked on in this study was intended to give a qualitative inspired account of the views and observation of those affected by underperformance as well as analysing documents (SMT minutes, reports and plans) and panellist documentation of the SMT role in dispensing off with their fiduciary activities.

Although values were not developed through collective process, participants acceded to their importance as gathered from the findings, exposing the fact that the direction; guidance; support; and development by the SMT should underlie values. This could be achieved through the interconnectivity of values and performance. The implication is that having shared values would, for instance make managing and leading daily activities and operations practicable as stated in the findings. This could lead to improved sustained performance whereby every activity is underpinned by an operational value which is drawn from multicultural concepts borne from the collaborative effort and adapted from the code of relations and influence. Again, shared values could precipitate teaming which is a critical component that warrants the SMT to share responsibilities as well as individual and collective ownership of agreements as deducted from the findings of the observations conducted. 


\section{Conclusion}

The preceding discussion brought to sharp focus the interrelationship and interconnectedness (I \& I) between beliefs, culture and values as well as attitude. That is found to be directly linked to the sort of environment prevalent at any given time. If the I \& I is condescending, the school will underperform. However if they $(I$ \& I) are favourable, then a setting where teachers teach, learners learn and stakeholders provide requisite support will prevail. Weaving the values into all operations and activities is the art of the probable. This implies that values are enablers of things to happen in order to raise the performance bar. The SMT has to consequently use a three pronged approach (adapted from Manning, 2001: 14) in a bit to lace their context with values and preserve an interactive setting:

$>$ Decision making. They together with other stakeholders, have to agree on suitable values. What values best describe their institution and how they will fuse them in all their operations and activities.

$>$ Gain trust. They have to earn others reliance and strive for accord within their setting.

$>$ Capacity building. Push for up skilling and increasing knowledge of those who are charged with a responsibility of teaching. This requires diligent appraisal approaches and management of quality in order that areas for building capacity can be identified and development be sourced.

The above will enable a mutually beneficial context that gives rise to performance from poor to fair, to good and then to excellent. The SMT remains the leadership corps that determines temperament of their institution. The value system decided upon should bring about a culture that motivates, inspires, is vision driven, provides leadership that guides and brings about fundamental competitive streak and interconnected approach to operations. This highlight: the need to take charge and certify that their (SMT) unpalatable personal values that may be a threat to their progress (of improvement) and strive to rid them off; establish pressure points and means of letting off steam; strive to resist tendencies that will stray them; build on their strengths and agreeable values in order to hold on to their newly found success venture.

\section{References}

Beare, H. 2001. Creating the Future School. London: British Cataloguing in Publication Data.

Begley, P.T. \& Leonard, T. 1999. Values and Educational Leadership. Albany: State University of New York Press.

Bell, L. \& Chan, D.W.K. 2005. Principas' Leadership and Srategic Planning in Primary Schools in Hong Kong and England: A comparison. Journal of the Commonwealth Council for Educational Administration and Management - CCEAM. Volume 33. Number 3. $2-21$.

Broodryk, J. 2006. Ubuntu: Life-coping skills. From Africa. Johannesburg: Knowres Publishing.

Bush, T. Kiggundu, E. \& Moorosi, P. 2011. Preparing New Principals in South Africa: the ACE: School Leadership Programme. South African Journal of Education. Vol. 31.31 - 43. EASA.

Department of Education. South African Schools Act 84 1996. Republic of South Africa. As amended by education laws Amendment Act 2007. Pretoria.

Department of Education, 2003. Resolution 8: Integrated Quality Management Systems.

Department of Education, 2010. Under Performing Secondary School Report. Quality Assurance Directorate. Gauteng.

Dewey, J. 1938. Experience and Education. New York: Collier Books.

Fidler, B. \& Atton, T. 1999. Poorly Performing Staff in Schools and How to Manage Them: capability, competence and motivation. London: Routledge.

Frere, P. 1973. Education for Critical Consciousness. New York: Seaburry Press.

Gauteng Department of Education. 2007. Circular 38. Responsibilities of SMTs. Johannesburg

Gauteng Department of Education. 2008. Circular 25. School Improvement Planning. Johannesburg

Gauteng Department of Education. 2009. Circular 15. Underperforming Schools. Johannesburg.

Grobbelaar, R. 2011. Teacher unions 'fail' pupils. In The Times. 8 September.

James, C. Connolly, M. Dunning, G. \& Elliot, T. 2008. High Attainment Schools in Disadvantaged Settings: An Interpretation of Significant Characteristics from a System Psychodynamis Perspective. Journal of commonwealth Council for Educational Administration \& Management. Volume 36. Number 2. 66-79.

Leithwood K, Day C, Sammons P, Harris A \& Hopkins D. 2006. Seven Strong Claims about Successful Leadership. London: Department of Education and Skills.

Manning, T. 2001.making sense of strategy. Cape Town: Zebra. ISBN 1-86872-353-4.

Marx. K. 1847. http://www.lawofvalues-wikipedia. Marx. Accessed - 2011/05/12.

Matthew Goniwe School of Leadership and Governance. 2011. Understanding School Management in South African Context. Advanced Certificate in Education (School Management and Leadership). Core Unit std: US ID 115441.

Maxwell, J. 2010. The 4 Pillars of Leadership. Tenth Impression. Cape Town: Struik Christian Books.

Mbiti, J. 1990. African Religions \& Philosophy. Second Edition. Oxford: Heinemann. 
McKenzie Report. 2010. How the world's most improved schools keep getting better? A video port cast with leading educationists (Fullen) from four countries (Canada, USA, Japan \& South Africa) respectively. October 29 9:00 am EST, 2:00 pm GMT and 10:00 pm JKT. Downloaded 23 May 2011.

Ngami, H. 2011. RARE book by a RARE woman. In UNISAWISE: Rooted in Africa. Winter 2011.

Phorabatho, T.A. 2010. Managing the Implementation of the National Curriculum Statement as Curriculum Change in Moretele Secondary Schools. Med Dissertation. University of South Africa.

Ramphele, M. 2012. CONVESATIONS with my Sons and Daughters. Johannesburg: Penguin Books.

Rintoul, M. \& Goulais, L. 2010. Vice Principalship and Moral Literacy: Developing Moral Compass. Educational Management Administration \& Leadership 38(6) 745-757. SAGE.

Schreuder, J. \& Landey, V. 2001. Compass for school-based management. Cape Town: Renaissance.

Schuitema, E. 2004. (a). Leadership: The Care and Growth Model. Cape Town: Ampersand Press.

Schuitema, E. 2004. (b). Intent: Exploring the Core of Being Human. Cape Town: Ampersand Press.

Sharma, R. 2010. The leader who had no title: a modern fable on real success in business and in life. Sydney: Simon \& Schuster.

Singo, M.J. 2003. Institutional Image as an aspect of marketing. Unpublished minor Dissertation. Johannesburg: University of Johannesburg.

Summit Documents-Commissions. 2011. Soweto Summit09 April.

The Education Handbook: connecting to make a difference. Produced by ARGO and supported by Sunday Times. 2011. Inspired by 100 ways to change our future by Education Roundtable.

Vally, S. Chisholm, L. \& Motala, S. 1999. Poverty \& Inequality Hearings Education Theme. Education Policy Unit: University of the Witswatersrand (EPU - Wits). Johannesburg.

Values Mate. 2009. Edition 1. Department of Basic Education. Republic of South Africa.

Values Education. 2011. Poster. MacEwan.

Winter, S. 2011. The return of panel inspections: The Solution to South Africa's Education Crisis? In the Business of Teaching: the South African rducation magazine. First Term. Cape Town: Absolutely Write! cc. II, http://www.bbc.co.uk/news/education11331574-accessed- 18 September 2010. 